\title{
Better RAFT Control is Better? Insights into the Preparation of Monodisperse Surface-functional Polymeric Microspheres by Photoinitiated RAFT Dispersion Polymerization
}

Liangliang Yu ${ }^{\mathrm{a}}$, Xiaocong Dai ${ }^{\mathrm{a}}$, Yuxuan Zhang ${ }^{\mathrm{a}}$, Zhaohua Zeng ${ }^{\mathrm{c}}$, Li Zhang ${ }^{\mathrm{a}, \mathrm{b}}$, Jianbo Tan $^{\text {*a, }}$

a. Department of Polymeric Materials and Engineering, School of Materials and Energy, Guangdong University of Technology, Guangzhou 510006, China.

b. Guangdong Provincial Key Laboratory of Functional Soft Condensed Matter, Guangzhou 510006, China.

c. School of Materials Science and Engineering, Sun Yat-sen University, Guangzhou 510275, China

Liangliang Yu and Xiaocong Dai contributed equally to this work.

*Corresponding authors: tanjianbo@gdut.edu.cn 


\section{EXPERIMENTAL SECTION}

\section{Materials.}

Methyl methacrylate (MMA, Aladdin) was passed through a column of basic alumina (Aladdin) prior to storage under refrigeration at $4{ }^{\circ} \mathrm{C}$. 2-methoxyethyl acrylate (MEA, Aladdin), glycidyl methacrylate (GlyMA, Aladdin), tert-butyl acrylate ( $t \mathrm{BA}$, Aladdin), benzyl methacrylate (BzMA, Aladdin), ethylene diamine anhydrous (EDA, Tianjin Damao Chemical Reagent Factory), magnesium sulfate $\left(\mathrm{MgSO}_{4}\right.$, Tianjin Damao Chemical Reagent Factory), trioxane (Aladdin), 2,2-dimethyl-2-phenylacetophenone (HMPP, Aladdin), and 4,4'-azobis(4-cyanovaleric acid) (ACVA, Aladdin) were used without further purification. 4-Cyano-4-(dodecylsulfanylthiocarbonyl) sulfanylpentanoic acid (CDPA) was synthesized according to the literature ${ }^{1}$. S-1-dodecyl-S'-( $\alpha, \alpha^{\prime}$-dimethyl- $\alpha^{\prime \prime}$-acetic acid) trithiocarbonate (DDMAT) was synthesized using a published procedure ${ }^{2}$.

\section{Characterization.}

Scanning electron microcopy (SEM). SEM images were collected using a Hitachi SU8010 (Tokyo, Japan) electron microscope at $5-10 \mathrm{kv}$ on samples sputter-coated with gold prior imaging. The samples for SEM imaging were prepared by drop casting the diluted dispersion on clean mica films and dried at room temperature prior to sputter-coating. SEM images were analyzed by using the software program named Image pro Plus 6.0. The average diameter $\left(d_{\mathrm{n}}\right)$ and coefficient of variation of diameter $\left(C_{\mathrm{v}}\right)$ were calculated according to the following equations:

$$
\begin{aligned}
& d_{n}=\sum_{i=1}^{n} d_{i} / n \\
& C V_{d}=\sqrt{\frac{\sum_{i=1}^{n}\left(\mathrm{~d}_{i}-d_{n}\right)^{2}}{n-1} / d_{n}}
\end{aligned}
$$

Transmission Electron Microscopy (TEM). The obtained dispersions were diluted 100-fold with water. A drop of the solution was placed on the copper grip for $1 \mathrm{~min}$ and then blotted with filter paper to remove excess solution. TEM observations were carried out on a Hitachi 7700 instrument operated at $120 \mathrm{kV}$.

Gel Permeation Chromatography $(G P C)$. The molecular weight and polydispersity of the block 
copolymers were measured by gel permeation chromatography (GPC) using a Waters 1515 GPC instrument with dimethylformamide (DMF) as the mobile phase and Waters styragel HR1, HR4 columns. The eluent was HPLC grade DMF containing $10 \mathrm{mM} \mathrm{LiBr}$ and was filtered prior to use. The flow rate of DMF was $1.0 \mathrm{~mL} / \mathrm{min}$. Linear poly (methyl methacrylate) polymers with narrow molecular weight distributions were used as the standards to calibrate the apparatus.

${ }^{1} H$ NMR Spectroscopy. Nuclear magnetic resonance (NMR) spectra were recorded in DMSO- $d_{6}$ using a Bruker Avance III $400 \mathrm{MHz}$ NMR spectrometer at a temperature of $25^{\circ} \mathrm{C}$.

Fourier transform infrared (FTIR). Each lyophilized sample in advance was ground up with $\mathrm{KBr}$ to form a fine power and compressed into a pallet. The FTIR spectra were recorded using a Nicolet 6700 spectrometer.

Contact angle analyzer. Water contact angles were recorded with an ultrapure water droplet of 8 $\mu \mathrm{L}$ on a contact angle analyzer (Chengde Jinhe Instrument Manufacturing Co., Ltd.) at room temperature. All the contact angle values were determined by averaging the values measured five different points on each sample surface.

\section{Synthesis of PGMA41.5-CDPA}

Synthesis of glycerol monomethacrylate (GMA). Glycidyl methacrylate (40.0 g) was added to water $(360.0 \mathrm{~g}, 10 \% \mathrm{w} / \mathrm{w})$ in a round bottom flask connected with a condenser while stirred for $9 \mathrm{~h}$ at $80{ }^{\circ} \mathrm{C}$. The resulting solution was then saturated with $\mathrm{NaCl}$ and extracted with dichloromethane. The organic phase was dried with anhydrous sodium sulfate overnight, filtered, and concentrated with rotary evaporator. The obtained monomer was further purified by silica column chromatography $\left(\mathrm{CH}_{2} \mathrm{Cl}_{2}: \mathrm{CH}_{3} \mathrm{OH}=20: 1, \mathrm{v} / \mathrm{v}\right)$, and then dried at $45^{\circ} \mathrm{C}$ under vacuum for the next step.

GMA (30.5 g, $0.19 \mathrm{~mol})$, ACVA (0.214 g, $0.76 \mathrm{mmol})$, CDPA (1.538 g, $3.80 \mathrm{mmol})$, and trioxane $(1.714 \mathrm{~g}, 0.019 \mathrm{~mol})$ were added into a $150 \mathrm{~mL}$ round-bottom flask, and then dissolved with anhydrous ethanol $(45.75 \mathrm{~g}, 40 \% \mathrm{w} / \mathrm{w})$ to form a homogeneous solution. Trioxane was used as the internal standard for NMR analysis. The reaction mixture was purged with nitrogen for $1 \mathrm{~h}$, sealed, and then immersed in a pre-heated oil bath $\left(70{ }^{\circ} \mathrm{C}\right.$ ) for $2.5 \mathrm{~h}$ (Monomer conversion $=83.0 \%$ as judged by ${ }^{1} \mathrm{H}$ NMR). The polymerization was quenched by immersion in ice-water and exposure to air. The polymer was precipitated by continuously dropped into the stirred $n$-hexane $(400 \mathrm{~mL})$ and washed several times with additional $n$-hexane. The obtained product was dried at $45{ }^{\circ} \mathrm{C}$ under vacuum overnight, and then analyzed by ${ }^{1} \mathrm{H}$ NMR spectroscopy and DMF GPC. ${ }^{1} \mathrm{H}$ NMR 
measurement indicated a mean degree of polymerization of 41.5 for this macro-CTA and DMF GPC measurement confirmed its $M_{\mathrm{n}}=15.3 \mathrm{~kg} / \mathrm{mol}$ and $M_{\mathrm{w}} / M_{\mathrm{n}}=1.30$.

\section{Synthesis of PGMA41.5- $b$-MEA3.3-CDPA}

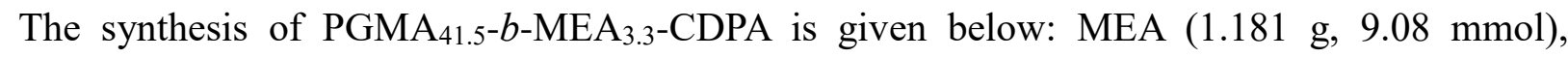
PGMA41.5-CDPA (16.0 g, $2.27 \mathrm{mmol})$, ACVA (0.1272 g, $0.45 \mathrm{mmol})$, and trioxane (0.082 g, 0.91 mmol) were added into a $150 \mathrm{~mL}$ round-bottom flask, and then dissolved with anhydrous ethanol/water $(34.51 \mathrm{~g} / 23.01 \mathrm{~g}, 60 / 40, \mathrm{w} / \mathrm{w})$. The reaction mixture was purged with nitrogen for $1 \mathrm{~h}$, sealed, and then immersed in a $70{ }^{\circ} \mathrm{C}$ oil bath for $4 \mathrm{~h}$ (Monomer conversion $=81.6 \%$ as judged by ${ }^{1} \mathrm{H}$ NMR). The polymerization was quenched by immersion in ice-water and exposure to air. The polymer was precipitated by continuously dropped into the stirred $n$-hexane $(400 \mathrm{~mL})$ and washed several times with additional $n$-hexane. The obtained product was dried at $45{ }^{\circ} \mathrm{C}$ under vacuum overnight, and then analyzed by ${ }^{1} \mathrm{H}$ NMR spectroscopy and DMF GPC. ${ }^{1} \mathrm{H}$ NMR measurement indicated a mean degree of polymerization of 3.3 for this macro-CTA, and DMF GPC measurement confirmed its $M_{\mathrm{n}}=16.6 \mathrm{~kg} / \mathrm{mol}$ and $M_{\mathrm{w}} / M_{\mathrm{n}}=1.35$.

\section{Photoinitiated RAFT Dispersion Polymerization}

In a typical experiment, MMA (2.0 g, $10 \mathrm{wt} \%$ relative to the reaction mixture), PGMA41.5-MEA $3.3-\mathrm{CDPA}(0.1 \mathrm{~g}, 5 \mathrm{wt} \%$ relative to the MMA), DDMAT(5 mg, $0.25 \mathrm{wt} \%$ relative to MMA) and HMPP (0.08 g, $4 \mathrm{wt} \%$ relative to MMA) were dissolved in an ethanol/water (7.2 g/10.8 g, 40/60, w/w) mixture to form a homogeneous solution. The reaction mixture was purged with nitrogen for $20 \mathrm{~min}$, sealed, and then irradiated with a LED lamp $\left(365 \mathrm{~nm}, 11.5 \mathrm{~mW} / \mathrm{cm}^{2}\right)$ for $2 \mathrm{~h}$ at room temperature. The microspheres were purified by three cycles of centrifugation-redispersion in ethanol/water (40/60, w/w) and finally dispersed into water.

\section{Two-Stage Photoinitiated RAFT Dispersion Polymerization}

In a typical experiment, MMA (2.0 g, $10 \mathrm{wt} \%$ relative to the reaction mixture), $\mathrm{P}\left(\mathrm{GMA}_{41.5}-b-\mathrm{MEA}_{3.3}\right)$-CDPA (0.1 g, $5 \mathrm{wt} \%$ relative to the MMA), DDMAT (5 mg, $0.25 \mathrm{wt} \%$ relative to MMA ), trioxane (0.180 g), HMPP (0.08 g, $4 \mathrm{wt} \%$ relative to MMA) were dissolved in an ethanol/water (7.2 g/10.8 g, 40/60, w/w) mixture. The reaction mixture was purged with nitrogen for $20 \mathrm{~min}$, sealed, and then a LED lamp $\left(365 \mathrm{~nm}, 11.5 \mathrm{~mW} / \mathrm{cm}^{2}\right)$ was employed to irradiate the reaction mixture. After $2 \mathrm{~h}$ of irradiation at room temperature, a degassed solution (containing $2.0 \mathrm{~g}$ of MMA, $0.08 \mathrm{~g}$ of HMPP, $0.180 \mathrm{~g}$ of trioxane, and ethanol/water(3.2 g/4.8 g)) was added into the reaction and 
irradiated for another $2 \mathrm{~h}$. The product was purified by three cycles of centrifugation-redispersion in ethanol/water (40/60, w/w) and finally dispersed in water.

\section{Synthesis of EDA-functionalized PMMA/PGlyMA microspheres}

PMMA/PGlyMA microspheres $(1.0 \mathrm{~g})$ dispersed in $20 \mathrm{~mL}$ water were added into a $50 \mathrm{~mL}$ round-bottom flask. $3 \mathrm{~mL}$ of EDA was added in the reaction mixture and stirred for $24 \mathrm{~h}$ at room temperature. The EDA-functionalized PMMA/PGlyMA microspheres were purified by three cycles of centrifugation-redispersion in water.

\section{Kinetics of Photoinitiated RAFT Dispersion Polymerization of MMA using PGMA41.5- $b$-PMEA3.3-CDPA as Macro -RAFT agent}

MMA (2.0 g, $10 \mathrm{wt} \%$ relative to the reaction mixture), PGMA $_{41.5}-b$-PMEA $3.3-\mathrm{CDPA}(0.1 \mathrm{~g}, 5$ $\mathrm{wt} \%$ relative to MMA), DDMAT (5 $\mathrm{mg}, 0.25 \mathrm{wt} \%$ relative to MMA ), trioxane (0.180 g), and HMPP (0.08 g, $4 \mathrm{wt} \%$ relative to MMA) were added in a $25 \mathrm{~mL}$ two-neck round bottom flask and dissolved with ethanol/water $(7.2 \mathrm{~g} / 10.8 \mathrm{~g})$. The reaction mixture was purged with nitrogen for $30 \mathrm{~min}$, sealed, and then irradiated with a LED lamp $\left(365 \mathrm{~nm}, 11.5 \mathrm{~mW} / \mathrm{cm}^{2}\right)$ for $2 \mathrm{~h}$ at room temperature. Samples were withdrawn at predetermined times with syringes under nitrogen, and the reaction was quenched by exposure to air and addition of a small amount of hydroquinone. The samples were then analyzed by ${ }^{1} \mathrm{H}$ NMR spectroscopy, SEM and DMF GPC.

\section{Colloidal stability experiments.}

Selected PMMA microspheres $\left(1 \mathrm{~mL}, 1 \mathrm{wt} \%\right.$ solids content) were frozen at $-20^{\circ} \mathrm{C}$ for 2 days in $1.5 \mathrm{~mL}$ Centrifuge tube, and then allowed to thaw at room temperature. Flocculation was judged by visual inspection.

Selected PMMA microspheres (100 $\mu \mathrm{L}, 5 \mathrm{wt} \%$ solids content) were transferred via a pipet into $1.5 \mathrm{~mL}$ centrifuge tube to which $900 \mu \mathrm{L}$ aliquots of various $\mathrm{MgSO}_{4}$ aqueous solutions were added (0.005-0.25 M), Colloidal stability was judged by visual inspection. 


\section{ADDITIONAL RESULTS}

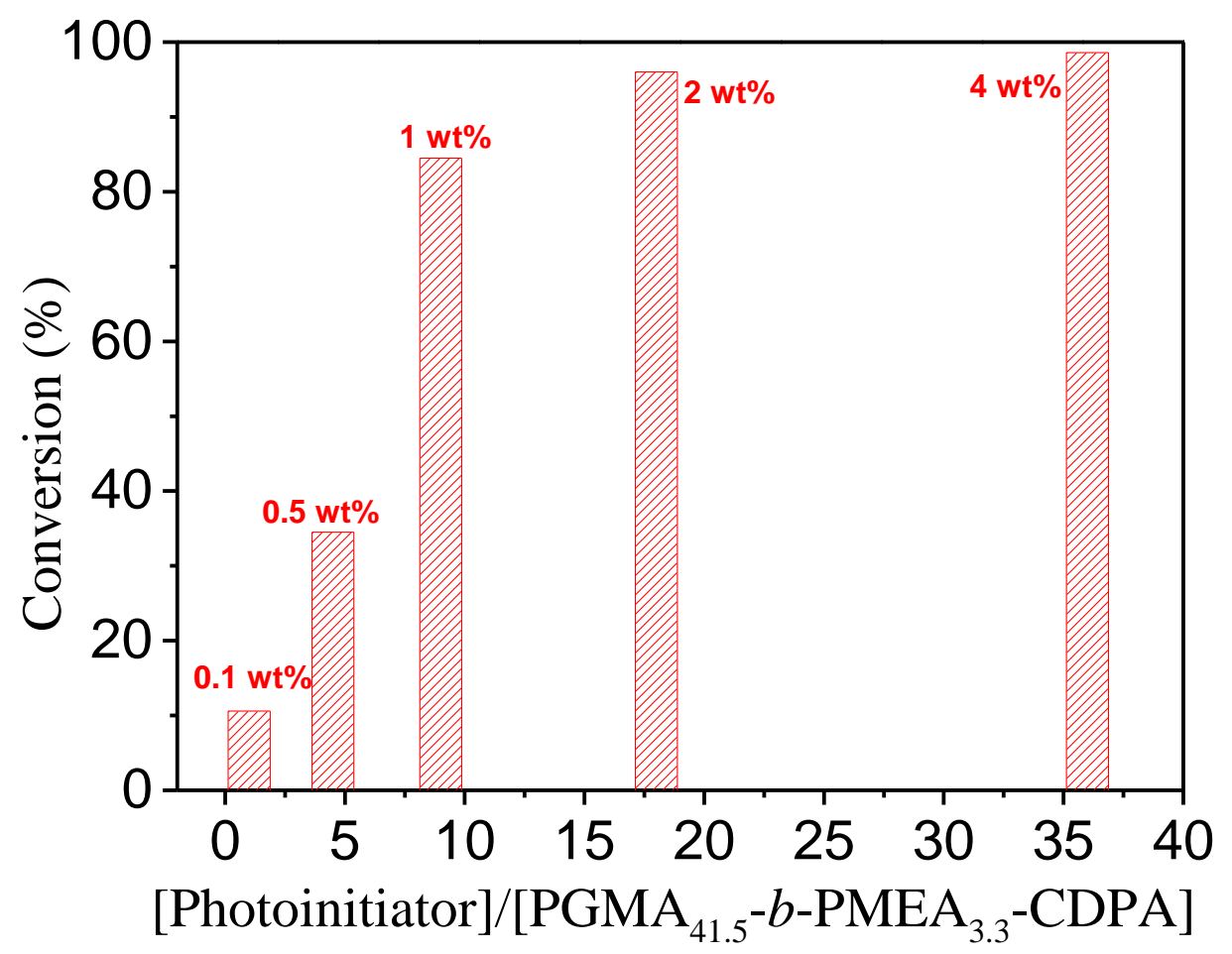

Figure S1. Evolution of conversion with photoinitiator concentration in photoinitiated RAFT dispersion polymerization of MMA using PGMA41.5- $b$-PMEA $3.3-\mathrm{CDPA}(5.0 \mathrm{wt} \%)$ as the macro-CTA.
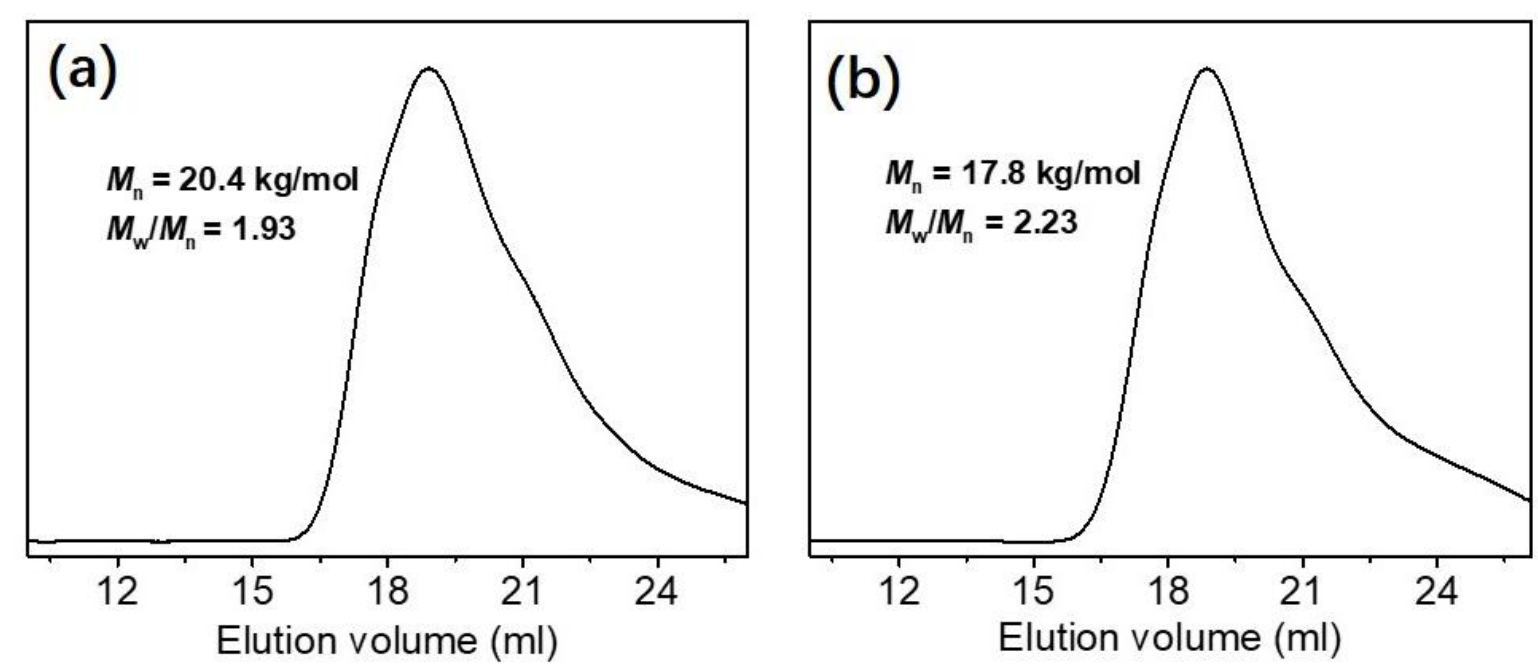

Figure S2. GPC traces of PMMA particles prepared by photoinitiated RAFT dispersion polymerization using $\mathrm{PGMA}_{41.5} \mathrm{CDPA}$ or $\mathrm{PGMA}_{41.5}-b-\mathrm{PMEA}_{3.3}-\mathrm{CDPA}$ as the macro-CTA (5.0 $\mathrm{wt} \%)$. 


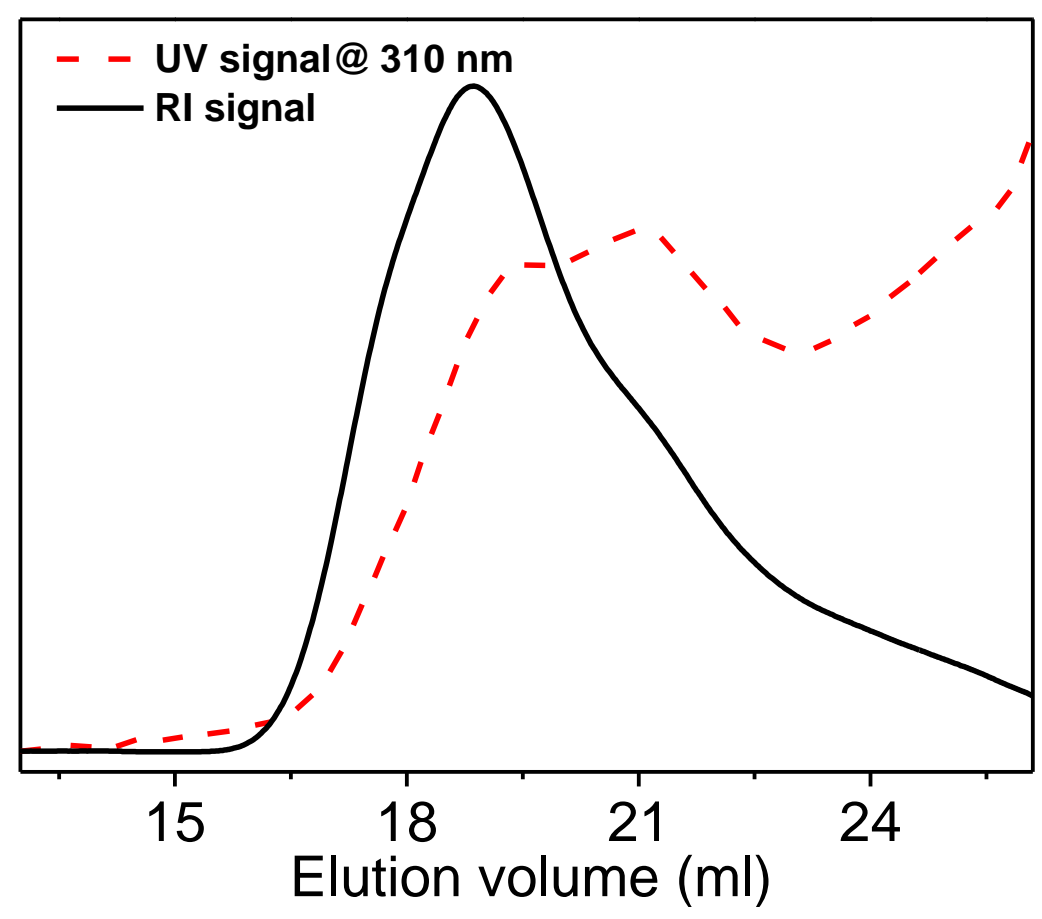

Figure S3. RI and UV (measured at $310 \mathrm{~nm}$ ) GPC traces of PMMA particles prepared by

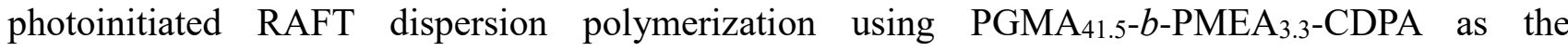
macro-CTA.

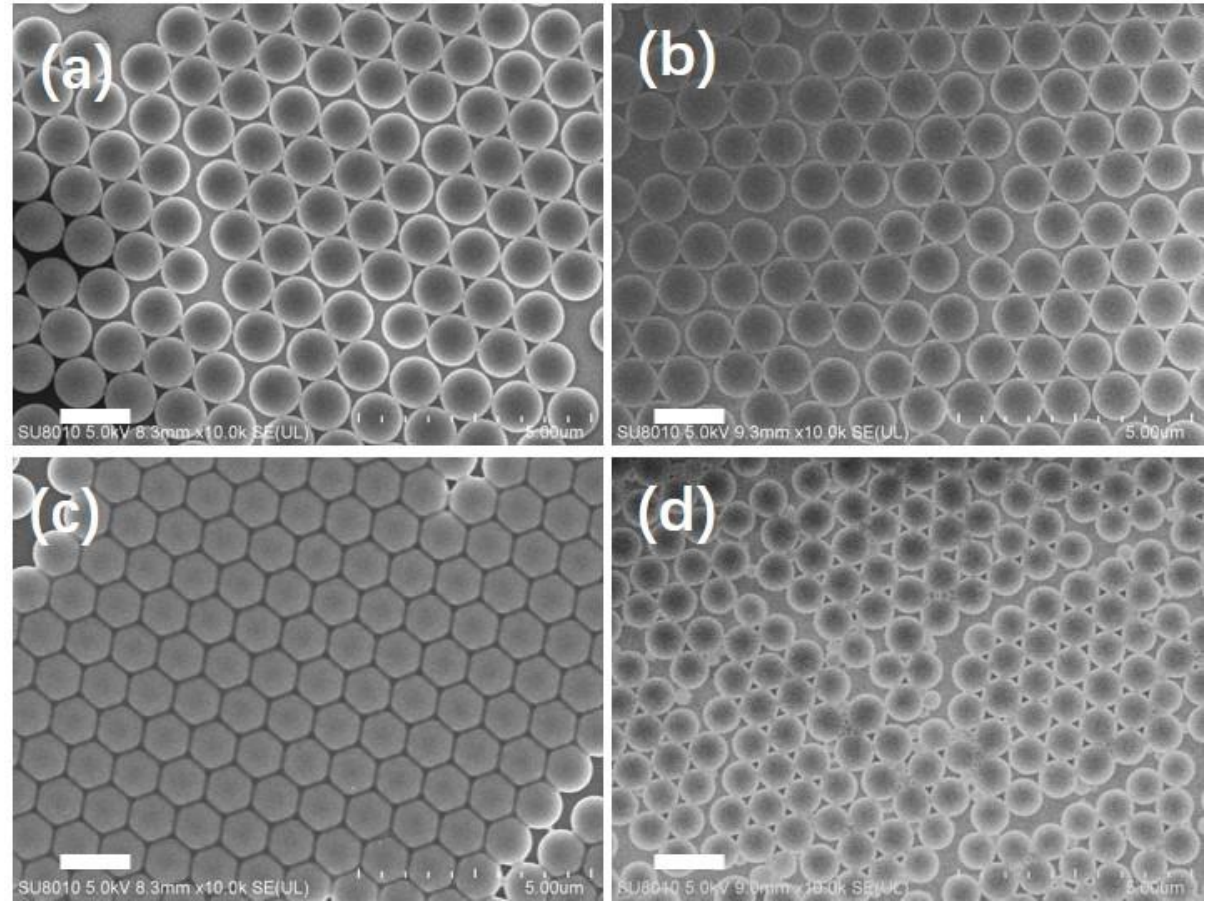

Figure S4. SEM images of PMMA microspheres prepared by photoinitiated RAFT dispersion polymerization of MMA using different amounts of PGMA $41.5-b$-PMEA 3.3 -CDPA. (a) $1.0 \mathrm{wt} \%$, (b) $2.0 \mathrm{wt} \%$, (c) 7.5 wt $\%$, (d) $10.0 \mathrm{wt} \%$. Scale bars: $2 \mu \mathrm{m}$. 

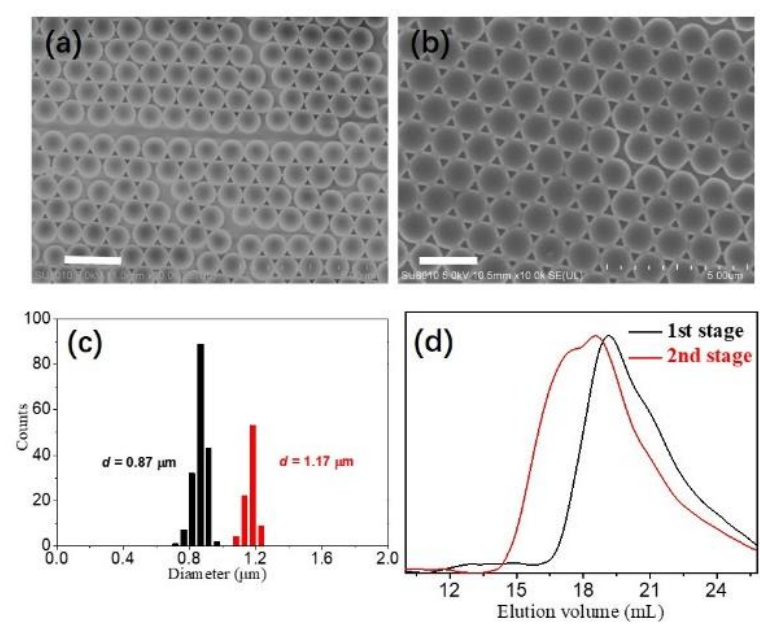
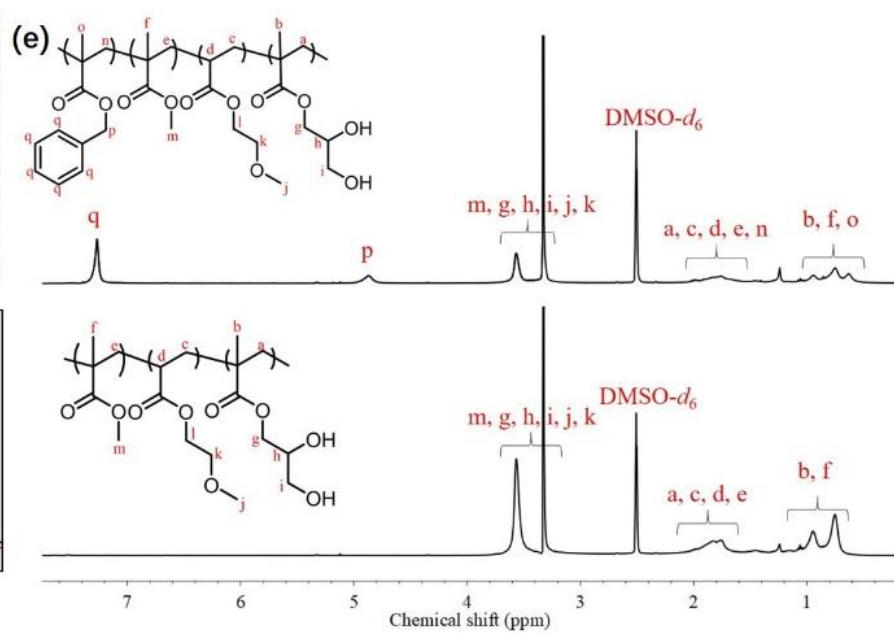

Figure S5. SEM images of PMMA microspheres $\left(1^{\text {st }}\right.$ stage, a) and PMMA/PBzMA microspheres $\left(2^{\text {nd }}\right.$ stage, $\left.b\right)$ prepared by two-stage photoinitiated RAFT dispersion polymerization of BzMA using 5 wt.\% PGMA $_{41.5-} b$-PMEA ${ }_{3.3}$-CDPA and $0.25 \mathrm{wt} . \%$ DDMAT ( $\mathrm{m} / \mathrm{m}_{0}$ ratio of 1.0). Scale bars: $2 \mu \mathrm{m}$. (c) Diameter histogram of PMMA microspheres ( $1^{\text {st }}$ stage) and PMMA/PBzMA microspheres ( $2^{\text {nd }}$ stage) prepared by two-stage photoinitiated RAFT dispersion polymerization of BzMA using 5 wt.\% PGMA $_{41.5}$-b-PMEA ${ }_{3.3}$-CDPA and 0.25 wt.\% DDMAT $\left(\mathrm{m} / \mathrm{m}_{0}\right.$ ratio of 1.0$)$. (d) GPC traces of PMMA microspheres ( $1^{\text {st }}$ stage) and PMMA/PBzMA microspheres ( $2^{\text {nd }}$ stage) prepared by two-stage photoinitiated RAFT dispersion polymerization of BzMA using 5 wt.\% PGMA $41.5-b$-PMEA 3.3 -CDPA and 0.25 wt.\% DDMAT ( $m / m_{0}$ ratio of 1.0$)$. (e) ${ }^{1} \mathrm{H}$ NMR spectra of PMMA microspheres $\left(1^{\text {st }}\right.$ stage $)$ and PMMA/PBzMA microspheres ( $2^{\text {nd }}$ stage $)$ prepared by two-stage photoinitiated RAFT dispersion polymerization of BzMA using 5 wt.\% PGMA $41.5-b$-PMEA $3.3-\mathrm{CDPA}$ and 0.25 wt.\% DDMAT $\left(\mathrm{m} / \mathrm{m}_{0}\right.$ ratio of 1.0).

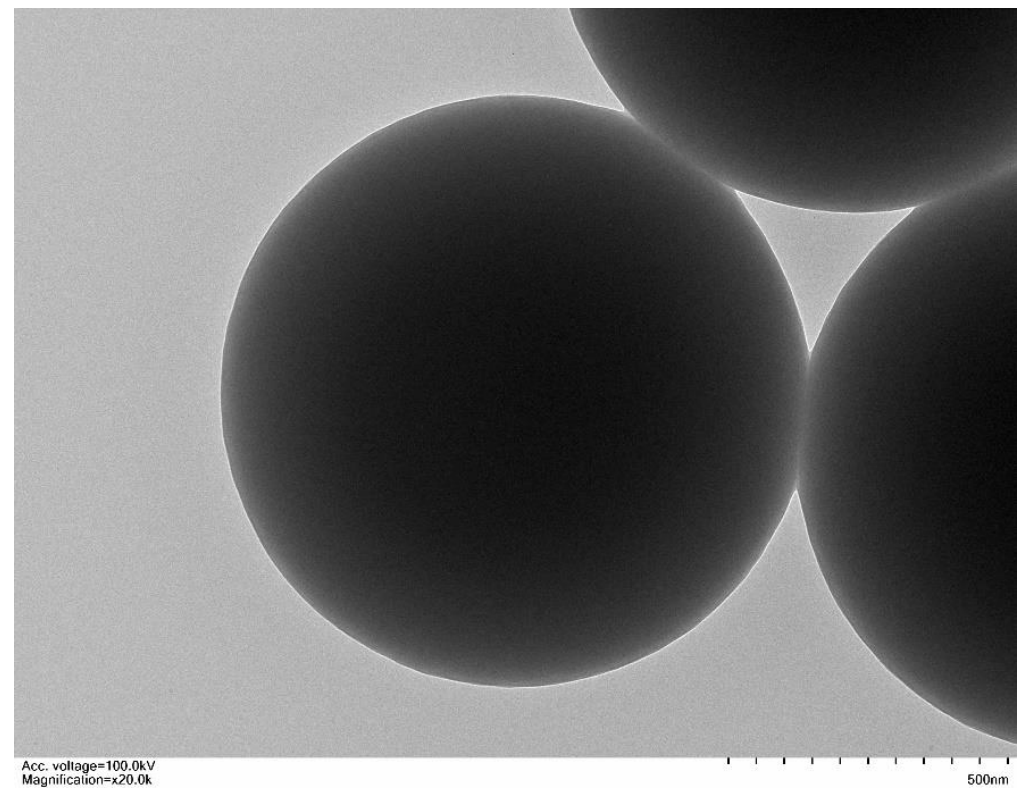

Figure S6. TEM image of EDA-functionalized PMMA/PGlyMA microspheres after dispersing in water.

\section{REFERENCE}

(1) Shen, W.; Chang, Y.; Liu, G.; Wang, H.; Cao, A.; An, Z. Biocompatible, Antifouling, and Thermosensitive Core-Shell Nanogels Synthesized by RAFT Aqueous Dispersion Polymerization. Macromolecules 2011, 44 (8), 2524-2530. https://doi.org/10.1021/ma200074n. 
(2) Lai, J. T.; Filla, D.; Shea, R. Functional Polymers from Novel Carboxyl-Terminated Trithiocarbonates as Highly Efficient RAFT Agents. Macromolecules 2002, 35 (18), 6754-6756. https://doi.org/10.1021/ma020362m. 